\title{
Orthogonal Experimental Design of Lifting Beam of Prefabricated Cabin Based on ANSYS Workbench
}

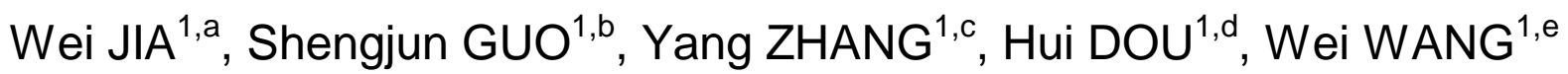 \\ ${ }^{1}$ XJ Electric Co., Ltd, Xuchang, 461000, China \\ azzzx_jiawei@126.com, bzzzx_guoshengjun@126.com, 'czzx_zhangyang@126.com, \\ dzzzx_douhui@126.com, 'zzzx_wangwei@126.com
}

\begin{abstract}
Keywords: prefabricated cabin, lifting beam, orthogonal experiment design, Workbench
Abstract. 16 different combined schemes, which solve the combined problem of section steel's specification, thickness of lifting plate and welding form of section steel, are designed basing on orthogonal experiment design method. Simulation experiments for 16 schemes are accomplished by using ANSYS Workbench platform. The simulation results are analyzed by range analysis and variance analysis. The combined scheme of factors which satisfies that von-Mises equivalent stress and structural deformation of lifting beam are the least is obtained. This design and analysis method has strong generality in structural design of products.
\end{abstract}

\section{Introduction}

Basing on the theory of standardized design and modular construction, secondary combination devices for smart substation are installed in prefabricated cabin before ex-works delivery of prefabricated cabin. The wiring and commissioning work of secondary device are also completed in manufacturing factory. The application of secondary combination devices in prefabricated cabin not only achieves scale production, system integration and debugging, but also shortens construction period of substation, saves resources and reduces the life cycle cost $[1,2]$.

Lifting beam is one kind of special spreader beam for transport of prefabricated cabins. The structural strength calculation and analysis of the lifting beam is essential in order to ensure the reliability of hoisting operation and the safety of construction process. Many design factors such as section steel's specification, thickness of lifting plate and welding form of section steel influence structural strength of the lifting beam. It is hard to find the optimal form of lifting beam by using practical test. Furthermore, the significance of each factor on structural strength of the lifting beam is indefinite.

Orthogonal experiment design method and finite element analysis method are used to find out the combined scheme of factors which satisfies that Mises equivalent stress and structural deformation of the lifting beam are the least. Range analysis, variance analysis and significance test are used to analyze significance of each factor. This design and analysis method has strong feasibility and generality in structural design of products.

\section{Orthogonal Experiment Design and Result Analysis Methods}

Orthogonal Experiment Design Method. Orthogonal experiment design (OED) method [3,4] is a statistical method to find the optimal level of factors and utilize the orthogonal arrays to organize experiments by using the principle of probability theory and mathematical statistics. The OED method is developed to sample a small, but representative set of level combinations for test to obtain optimal combination of all factors. OED provides factors analysis and a series of orthogonal arrays, each of which ensures a balanced combination of levels for any factor[5].

Orthogonal array is a fractional factorial matrix of numbers arranged in rows and columns, where each row represents the levels of factors in each combination, and each column represents a specific factor that can be changed from each combination. In a discrete single-objective optimization problem, when there are $N$ factors and each factor has $Q$ levels, the search space consists of $Q^{N}$ combinations of 
factors. It may not be possible to do all $Q^{N}$ experiments to obtain the optimal solution especially while $N$ and $Q$ are large. The selected combinations are scattered uniformly over the space of all possible combinations $Q^{N}$ by using orthogonal array $\boldsymbol{L}_{M}\left(Q^{N}\right) . \boldsymbol{L}$ denotes a Latin Square and $M$ is the number of orthogonal tests. $\boldsymbol{L}_{M}\left(Q^{N}\right)$ is a matrix of numbers arranged in $M$ rows and $N$ columns.

In the orthogonal array, all columns can be evaluated independently of one another and the main effect of one factor does not bother the estimation of the main effect of another factor. For instance, the appropriate array for combination problem arranging five factors above four levels is $\boldsymbol{L}_{16}\left(4^{5}\right)$. There are 1024 combinations to be tested by using comprehensive method. The test cycle is very long and the test cost is also very high. However, just 16 representative combination schemes can find out the optimal level for each factor by using OED method. For this reason, OED method is adopted in this research. Basic Flow of OED Method. The OED method is used to organize experiment schemes and analyze experimental results scientifically before decision-making in this research[3]. The basic flow of OED method is described as follows:

Step1. Select the factors in orthogonal experiment and determine the level for each factor according to the analysis and discussion in section 2.

Step2. Select appropriate orthogonal array among all standard orthogonal arrays.

Step3. Arrange experiment schemes using orthogonal array and OED method, carry out experiments on PC and obtain the experimental results.

Step4. Range analysis. Find the optimal combination of all factors according to the results of range analysis; if the optimal combination is not in the orthogonal, further verification test is needed to illustrate its optimality.

Step5. Variance analysis. Calculate the sum of squares and $F$ value according to $F$-test and find the sensitive factors.

Analysis Method of Test Results. Range analysis and variance analysis are two common analysis methods in the analysis of orthogonal test results.

Range Analysis. Range is the difference between the highest and the lowest mean value of examinational index for different factors, which is symbolized as $R . \bar{y}_{j k}(k=1,2,3)$ is mean value of the experimental results with the same level of $k$ in the $j$ th column of the orthogonal array; $R_{j}$ is the range of $\bar{y}_{j k}$, and the expression is defined as

$R_{j}=\max \left(\bar{y}_{j 1}, \bar{y}_{j 2}, \bar{y}_{j 3}, \cdots\right)-\min \left(\bar{y}_{j 1}, \bar{y}_{j 2}, \bar{y}_{j 3}, \cdots\right)$

where $\bar{y}_{j 1}(j=1,2,3,4)$ is the average value of all experimental results for factor $j$ in level 1 .

Different factors have different impacts on the objective function. The bigger the range of one factor, the greater the impact it has. Range analysis is performed in order to find optimal level for each factor. Therefore, the optimal combination of four factors is obtained. However, the optimal combination doesn't always list in the standard array. Further experiment is need to verify the optimized combination of factors.

Variance Analysis. Variance analysis of is performed to discuss whether the factors are statistically significant or not. $F$-test is a powerful tool to observe which factor has a significant effect on the objective function[3]. The $F$-value is simply a ratio of the mean of the squared error.

Generally, the larger the $F$-value, the greater the effect of the factor. The significance level $\alpha$ contains three levels such as $0.01,0.05$ and 0.1 . According to the comparison of the $F$-value and $F_{\alpha}$, the significance level is divided into four grades[6]. If $F \geq F_{0.01}$, the significance level is high significant influence denoted as ' $* * *$ '; if $F_{0.01}>F \geq F_{0.05}$, the significance level is significant influence denoted as '**', if $F_{0.05}>F \geq F_{0.1}$, the significance level is less significant influence denoted as ' *'; if $F<F_{0.1}$, the significance level is no-significant influence denoted as ' $x$ '.

\section{Orthogonal simulation analysis for lifting beam of prefabricated cabin}

The Lifting Beam. The lifting beam shown in Fig.1 plays a very important role in transportation and lifting operation of prefabricated cabins[1]. The lifting beam is used to prevent the cabins losing balance and shaking. The material of lifting beam is Q235, material elastic modulus $E$ is 200GPa and 
Poisson's ratio is 0.3 . The calculating load for a single lifting beam is defined as 5 tons and the length of hoisting wire rope is 5 meters. Basing on ANSYS Workbench analysis platform, many design factors such as section steel's specification, thickness of lifting plate and welding form of section steel are considered to improve the structural strength of the lifting beam. Dynamic response and gravity are not considered in the simulation analysis of the lifting beam.

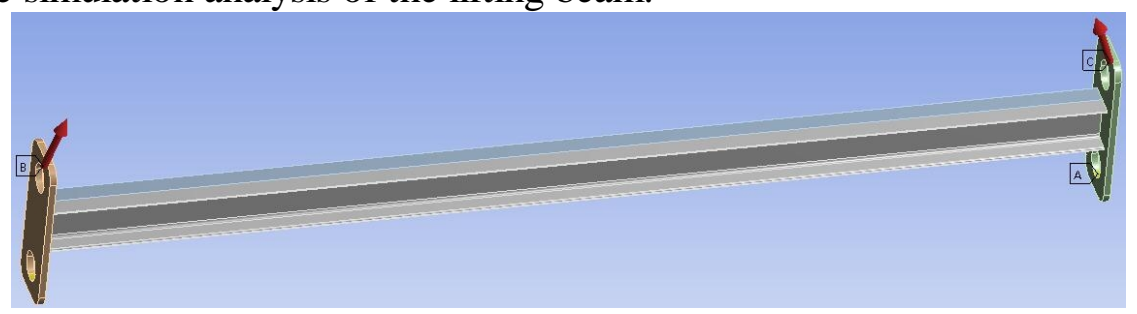

Fig.1 Lifting beam of prefabricated cabin

Orthogonal Experimental Design. The OED method is used to arrange the experiment scheme and utilize the properties of the fractional factorial experiment for the efficient judgment of the optimal combination of factors' levels.

Aim of the Study. In order to optimize the structural strength of the lifting beam, OED method is adopted here to find the optimal value of three design factors of the lifting beam.

Objective Function. Basing on orthogonal design method, the objective function is that von-Mises equivalent stress and structural deformation of lifting beam both are the least.

Design Factors. The main factors that could affect the structural strength are section steel's specification, thickness of lifting plate and welding form of section steel. They have been named as $A, B$ and $C$, respectively. Four levels for each factor are shown in Table 1.

\begin{tabular}{cccc} 
Table 1 & \multicolumn{2}{c}{ Factor levels of orthogonal experiment } \\
\hline Level & $A$ & $B$ & $C$ \\
\hline 1 & $14 \mathrm{a}$ & 16 & shedding to shedding \\
2 & $14 \mathrm{~b}$ & 20 & back-to-back \\
3 & $16 \mathrm{a}$ & 25 & (shedding to shedding) \\
4 & $16 \mathrm{~b}$ & 30 & (back-to-back) \\
\hline
\end{tabular}

Select Appropriate Orthogonal Array. Because welding form of section steel only has two levels, test scheme can not satisfy standard orthogonal arrays. Quasi Horizontal method[3] is used to expand the level of welding form of section steel into 4 levels. Among all standard orthogonal arrays, the appropriate one for arranging three factors with four levels is $L_{16}\left(4^{5}\right)$. The test scheme shown in table 2 is to investigate the effect of those factors on the structural strength of the lifting beam.

Table 2 Schemes and results of orthogonal experiment

\begin{tabular}{|c|c|c|c|c|c|}
\hline No. & $\begin{array}{l}\text { section steel's } \\
\text { specification }\end{array}$ & $\begin{array}{l}\text { Thickness of } \\
\text { lifting plate }\end{array}$ & $\begin{array}{l}\text { Welding form } \\
\text { of section steel }\end{array}$ & $\begin{array}{c}\text { Maximum value of Mises } \\
\text { equivalent stress/MPa }\end{array}$ & $\begin{array}{c}\text { Maximum value of } \\
\text { structural deformation/mm }\end{array}$ \\
\hline 1 & $14 \mathrm{a}$ & $16 \mathrm{~mm}$ & $\begin{array}{l}\text { shedding to } \\
\text { shedding }\end{array}$ & 311.210 & 1.59190 \\
\hline 2 & $14 \mathrm{a}$ & $20 \mathrm{~mm}$ & back-to-back & 144.930 & 1.06240 \\
\hline 3 & $14 \mathrm{a}$ & $25 \mathrm{~mm}$ & $\begin{array}{l}\text { shedding to } \\
\text { shedding }\end{array}$ & 157.430 & 0.88999 \\
\hline 4 & $14 \mathrm{a}$ & $30 \mathrm{~mm}$ & back-to-back & 92.186 & 0.85095 \\
\hline 5 & $14 b$ & $16 \mathrm{~mm}$ & back-to-back & 198.820 & 1.73330 \\
\hline 6 & $14 b$ & $20 \mathrm{~mm}$ & $\begin{array}{l}\text { shedding to } \\
\text { shedding }\end{array}$ & 226.790 & 1.03420 \\
\hline 7 & $14 \mathrm{~b}$ & $25 \mathrm{~mm}$ & back-to-back & 103.640 & 0.89723 \\
\hline 8 & $14 b$ & $30 \mathrm{~mm}$ & $\begin{array}{l}\text { shedding to } \\
\text { shedding }\end{array}$ & 116.330 & 0.84615 \\
\hline 9 & $16 a$ & $16 \mathrm{~mm}$ & $\begin{array}{l}\text { shedding to } \\
\text { shedding }\end{array}$ & 279.850 & 1.35530 \\
\hline 10 & $16 \mathrm{a}$ & $20 \mathrm{~mm}$ & back-to-back & 126.430 & 0.86815 \\
\hline
\end{tabular}




\begin{tabular}{|c|c|c|c|c|c|}
\hline 11 & $16 a$ & $25 \mathrm{~mm}$ & $\begin{array}{l}\text { shedding to } \\
\text { shedding }\end{array}$ & 139.750 & 0.60134 \\
\hline 12 & $16 a$ & $30 \mathrm{~mm}$ & back-to-back & 71.534 & 0.57573 \\
\hline 13 & $16 b$ & $16 \mathrm{~mm}$ & back-to-back & 179.890 & 1.42560 \\
\hline 14 & $16 b$ & $20 \mathrm{~mm}$ & $\begin{array}{l}\text { shedding to } \\
\text { shedding }\end{array}$ & 194.350 & 0.81465 \\
\hline 15 & $16 b$ & $25 \mathrm{~mm}$ & back-to-back & 88.021 & 0.59587 \\
\hline 16 & $16 b$ & $30 \mathrm{~mm}$ & $\begin{array}{l}\text { shedding to } \\
\text { shedding }\end{array}$ & 103.360 & 0.53206 \\
\hline
\end{tabular}

Range Analysis of Test Results. Comprehensive balance method and comprehensive evaluation method are two common analysis methods in the analysis of multi-objective experimental results. In this paper, comprehensive balance method is appropriate for the analysis of two examination indexes. The range analysis of test results is shown in table 3.

Table 3 Range analysis of experiment results

\begin{tabular}{|c|c|c|c|c|}
\hline \multirow{2}{*}{$\begin{array}{c}\text { Examination } \\
\text { index }\end{array}$} & & $A$ & $B$ & $C$ \\
\hline \multirow{4}{*}{$\begin{array}{c}\text { Maximum value } \\
\text { of Mises } \\
\text { equivalent } \\
\text { stress/MPa }\end{array}$} & $\bar{y}_{j 1}$ & 176.439 & 242.442 & 195.278 \\
\cline { 2 - 5 } & $\bar{y}_{j 2}$ & 161.395 & 173.125 & 125.826 \\
\cline { 2 - 5 } & $\bar{y}_{j 3}$ & 154.391 & 122.210 & 186.990 \\
\cline { 2 - 5 } & $\bar{y}_{j 4}$ & 141.405 & 95.853 & 125.537 \\
\cline { 2 - 5 } & $R_{j}$ & 35.034 & 146.589 & 69.741 \\
\cline { 2 - 5 } & Factors' effect & \multicolumn{3}{|c|}{$B>C>A$} \\
\hline \multirow{4}{*}{$\begin{array}{c}\text { Maximum value } \\
\text { of structural }\end{array}$} & $\bar{y}_{4} B_{4} C_{4}$ \\
\cline { 2 - 5 } deformation/mm scheme & 1.099 & 1.527 & 0.940 \\
\cline { 2 - 5 } & $\bar{y}_{j 2}$ & 1.128 & 0.945 & 0.992 \\
\cline { 2 - 5 } & $\bar{y}_{j 3}$ & 0.850 & 0.746 & 0.977 \\
\cline { 2 - 5 } & $\bar{y}_{j 4}$ & 0.842 & 0.701 & 1.010 \\
\cline { 2 - 5 } & $R_{j}$ & 0.286 & \multicolumn{3}{|c|}{0.826} & 0.070 \\
\cline { 2 - 5 } & Factors' effect & $A_{4} B_{4} C_{1}$ \\
\cline { 2 - 5 } & Optimal scheme & \multicolumn{3}{|c}{} \\
\hline
\end{tabular}

Factor $A$ is a minor factor to Mises equivalent stress, which is a secondary factor to structural deformation. Therefore, the optimal level for factor $A$ is $A_{4}$. Factor $B$ is a major factor to Mises equivalent stress, which is a major factor to structural deformation. Therefore, the optimal level for factor $B$ is $B_{4}$. Factor $C$ is secondary factor to Mises equivalent stress, which is a minor factor to structural deformation. Therefore, the optimal level for factor $C$ is $C_{4}$. In a word, the optimal combination scheme of four factors is $A_{4} B_{4} C_{4}$, which is not listed in standard orthogonal array. Further verification experiment is completed using this combination scheme to illustrate the optimality. The maximum value of Mises equivalent stress is $71.463 \mathrm{MPa}$ and the maximum value of structural deformation is $0.5355 \mathrm{~mm}$. The Mises equivalent stress and structural deformation using this scheme is less than other combination schemes. Therefore, the optimal combination of four design factors is $A_{4} B_{4} C_{4}$.

Variance Analysis of Test Results. Variance analysis is applied to distinguish the data fluctuation caused by the change of experimental condition and experimental error. Generally, the larger the $F$-value, the greater the effect caused by the change of the factor. The result of range analysis is expressed in table 4 and table 5. From the standard table of $F$ distribution, $F$-value are 6.99, 3.86 and 2.81 corresponding to three significance levels $0.01,0.05$ and 0.1 .

Basing on the results of $F$-test, we can obtain the conclusion that three factors denoted as ' $x$ ' have no-significant influence on both examinational indexes. However, the $F$-value of Maximum value of Mises equivalent stress and Maximum value of structural deformation for thickness of lifting plate are 
2.148 and 2.559, respectively. The influence of thickness of lifting plate is more significant than section steel's specification and welding form of section steel.

Table 4 Variance analysis on von-Mises equivalent stress

\begin{tabular}{ccccc}
\hline Source & $\begin{array}{c}\text { Sum of } \\
\text { squares }\end{array}$ & $\begin{array}{c}\text { Degree of } \\
\text { freedom }\end{array}$ & $F$ & Significance \\
\hline $\begin{array}{c}\text { Section steel's } \\
\text { specification }\end{array}$ & 2557.076 & 3 & 0.110 & $\times$ \\
$\begin{array}{c}\text { Thickness of } \\
\text { lifting plate }\end{array}$ & 50007.420 & 3 & 2.148 & $\times$ \\
$\begin{array}{c}\text { Welding form } \\
\text { of section steel } \\
\text { Error }\end{array}$ & 17273.587 & 3 & 0.742 & $\times$ \\
\hline
\end{tabular}

Table 5 Variance analysis on structural deformation

\begin{tabular}{ccccc}
\hline Source & $\begin{array}{c}\text { Sum of } \\
\text { squares }\end{array}$ & $\begin{array}{c}\text { Degree of } \\
\text { freedom }\end{array}$ & $F$ & Significance \\
\hline $\begin{array}{c}\text { Section steel's } \\
\text { specification }\end{array}$ & 0.287 & 3 & 0.425 & $\times$ \\
$\begin{array}{c}\text { Thickness of } \\
\text { lifting plate }\end{array}$ & 1.729 & 3 & 2.559 & $\times$ \\
$\begin{array}{c}\text { Welding form } \\
\text { of section steel } \\
\text { Error }\end{array}$ & 0.011 & 3 & 0.016 & $\times$ \\
\hline
\end{tabular}

\section{Conclusions}

This paper study the optimal combined problem of design factors of the lifting beam. 16 different combined schemes are designed basing on orthogonal experiment design method. Simulation experiment for those 16 schemes is accomplished by using ANSYS Workbench platform. The optimal combined scheme of factors is obtained. When the section steel's specification is $16 \mathrm{~b}$, the thickness of lifting plate is $30 \mathrm{~mm}$ and the welding form of section steel is shedding to shedding, maximum value of von-Mises equivalent stress and maximum value of structural deformation of lifting beam are the least. The thickness of lifting plate has significant influence on von-Mises equivalent stress of lifting beam and structural deformation. The OED method is feasible, reasonable and reliable. It has a strong universal use and has important guiding significance in the design of enterprise products.

\section{References}

[1] W. Zhou and J. Li: Electrical Engineering, Vol. 15 (2014), p.88

[2] X.Q. Zhu and Y.Z. Wei: Energy and Environment, Vol. 22 (2015), p.26

[3] K. Chen: Experinmental Design and Analyses(2th ed) (Qinghua University Press, Beijing 2005)

[4] G.F. Chang, H.S. Ni, S.C. Xu, et al: Journal of Mechanical Engineering, Vol. 45 (2009), p.204

[5] Y.X. Du, W. Wang, Q.H. Tian: Machine Design and Research, Vol. 27 (2011), p.14

[6] W.T. Zhang, H.M. Yu: Safety and Environmental Engineering, Vol. 16 (2009), p.13 